American Journal of Infectious Diseases 7 (1): 24-27, 2011

ISSN 1553-6203

(C) 2011 Science Publications

\title{
Mycobacterium Smegmatis Infection of a Lumbar Spine Instrumented Fusion
}

\author{
Frank Allen Zimba \\ P.O. Box 203, Dunkirk, NY 14048
}

\begin{abstract}
Problem statement: To demonstrate the presentation of atypical mycobacterial postsurgical infections and their management. Approach: Single patient case report. Results: Successful management of atypical mycobacterial post operative infection with preservation of instrumented hardware posterior pedicle screw fixation and interbody cages. Conclusion: This report suggests that these atypical mycobacterial infections can be eradicated with successful outcomes with preservation of spinal instrumentation.
\end{abstract}

Key words: Atypical mycobacterial infections, post surgical infections, mycobacterial smegmatis

\section{INTRODUCTION}

Wound infections from atypical mycobacteria are uncommon, but are often detected because of recognition of their biological hardiness. Some of these atypical organisms can thrive at high temperatures of 45 $\mathrm{C}$ (centigrade) or above and resist sterilization with organomercurials (10\% Povidone-Iodine), Chlorine, $2 \%$ Formaldehyde, alkaline glutaradehyde and other commonly used disinfectants (Wallace et al., 1998). Post-operative infections have been reported in total joint arthroplasties, prosthetic breast implants (Widgerow et al., 1995), corneal (Lasik) and cataract procedures (Merani et al., 2008), vertebral or articular osteomyelitis (Astageneau et al., 2001; Danesh-Clough et al., 2000; Meier and Beekmann, 1995; Ollagnier et al., 1998; Pruitt et al., 1993; Smith, 1976; Han et al., 2007), sternotomies, soft tissue wound infections (Weed et al., 1956; Hand and Sanford, 1970), hernia 'mesh' repairs, abdominal wall abscesses, prosthetic cardiac valves, ventriculo-peritoneal shunts, after EMG-NCS procedures, catheter infections and postinjection abscesses (O'Brien and Rawluk, 1999; Kalita et al., 2005). Most early papers considered these postoperative wound infections to be related either to environmental factors or host factors, especially those associated with immunocompromised patients (Yano et al., 2004; Sumner et al., 2003). However; more recent studies show infections secondary to these organisms in non-immunocompromised patients (Danesh-Clough et al., 2000; Kalita et al., 2005; Watanakunakorn, C. and A. Trott, 1973; Rahman et al., 1992; Huang et al., 2000). Contamination has included water sources for chilled surgical solutions, sterilization equipment (Wallace et al., 1998; Huang et al., 2000; Thami et al.,
2002) and water sources (Wallace et al., 1998; SchulzeRobbecke et al., 1992; Wallace, 1987; Wright et al., 1985; Collins et al., 1984; Slosarek et al., 1993; Le Dantec et al., 2002; Bullin et al., 1970) and particularly hot water in hospitals (Astageneau et al., 2001; Wallace, 1987; Wright et al., 1985; Chada et al., 1998).

This case report identifies a case of Mycobacterium Smegmatis infecting a L5/S1 interbody fusion procedure with biological cure; without hardware removal. This study demonstrates the difficulty with timely identification (Meier and Beekmann, 1995; Pruitt et al., 1993; Weed et al., 1956; Corpe et al., 1961; Wallace et al., 1988; Brown et al., 1999; Marks and Schwabacher, 1965; Prosser, 1986; Cobbett, 1918), the need for increased vigilance for spread of the infection into deep tissues (Widgerow et al., 1995; Han et al., 2007; Plaus and Hermann, 1991), the role of multiple antibiotics/anti-fungals (Rahman et al., 1992; Corpe et al., 1961; Prosser, 1986; Nagao et al., 2009; Roche et al., 1997; Duttaroy et al., 2004) and the management of this infection similarly to that of TB infections (Weed et al., 1956; Watanakunakorn and Trott, 1973; Rahman et al., 1992; Prosser, 1986; Nagao et al., 2009; Roche et al., 1997), with ultimate resolution.

The case is presented below: $56 \mathrm{y} / \mathrm{o} \mathrm{WF}$ admitted for elective L5/S1 fusion and discectomy on 10-18-2004. Her prophylactic, pre-operative antibiotic coverage was Ancef $1 \mathrm{gm} \mathrm{IV}$. The patient was discharged to home on post-operative day \#4 with a dry, intact suture line. On post-operative day \#11, she underwent staple removal. She called on post-operative day \#21 for increased drainage from a re-opened incision. She was started on a trial of oral Keflex $500 \mathrm{mg}$ orally QID. Her C-reactive 
protein level and $\mathrm{CBC}$ were normal. Follow-up evaluation after 10 days of oral Keflex, revealed a persistent draining wound. A 'suture granuloma' at the draining site was suspected. Exploration under local anesthetic was performed on 12/2/2004. No granuloma was found. Instead a large subcutaneous purulent cavity was packed and a re-exploration was planned to r/o deep fascial infection. A serendipitous acid-fast stain of the purulent material revealed acid fast bacteria. On $12 / 3 / 2004$, she underwent formal exploration and packing, under general anesthesia. The thoracolumbar fascia was intact. Wound packing was initiated with saline soaked gauze dressing changes. She was discharged on a ten day antibiotic course (Keflex 500 mg QID) with a stable wound. Wound bacterial culture results reported on 12/8/2004 revealed Staphylococcus Epidermidis (2 species) one sensitive to Cephalothin; one resistant. A routine office visit on 12/15/2004 revealed the wound to be healing nicely off antibiotics. On 12/27/2004 we were notified by the New York State Laboratories that the acid fast bacterium was neither a Mycobacterium Tuberculosis nor Mycobacterium Avium. A follow-up visit on 1/14/2005, revealed a nearly healed wound. The NY State Laboratory identified a Mycobacterium Smegmatis on 1-17-2005. Because of increased symptoms of new left ankle and heel pain, the patient underwent a lumbar MRI with and without Gadolinium on 2-7-2005. This revealed a normal post-operative study. Her lumbar wound was well healed at follow-up on 2/11/2005.

On 2/14/2005 the patient was admitted to hospital due to worsening systemic symptoms-malaise, loss of weight and poor appetite. She was noted to have a rising ESR (from 55-96) and elevations in her C reactive protein level (1.8-13) and WBC (7.8-17.8). On the next day a CT of lumbar spine revealed a large subfascial, epidural fluid collection. On 2/16/2005, she underwent an operation with opening of the thoracolumbar fascia, exploration of the extradural space and debridement without finding liquid purulence. An AFB stain was negative. The patient was packed open with TID dressing changes to facilitate drainage and healing; and discharged home. A followup CT scan of the lumbar spine on 2/21/2005 showed persistent or increased fluid extradural collections despite the open wound. She was readmitted for a CT guided biopsy of the lumbar spine fluid collections. The paraspinal collection on $2 / 25 / 2005$ was positive for a greenish fluid aspirate. The patient was started on Amikacin, Ethambutal, Bactrim and Biaxin on $2 / 27 / 2005$. A repeat CT scan of the lumbar spine on $3 / 4 / 2005$ demonstrated reduction in the paraspinal fluid collections, with a clinically, improving fever curve. On
$3 / 7 / 2005$, the New York State Laboratory identified the 2/25/2005 CT aspirate as containing M. Smegmatis. The patient was discharged home on the above antibiotic regimen on 3/9/2005.

A repeat surveillance lumbar CT on 3/22/2005, unexpectedly, revealed the accumulation of a large psoas and lateral paraspinal of purulence. A CT guided abscess drainage procedure was undertaken with placement of a 10 Fr self-retaining catheter with $50 \mathrm{cc}$ of purulence drained! She was seen in my office on $3 / 30 / 2005$, with a nearly completely healed surgical wound and the draining "pig-tail" catheter. Clinically, she had an improving C-reactive protein and ESR.

A third surveillance CT of the lumbar spine on 4/11/2005 was obtained and revealed no residual fluid filled cavities. Her 'pig-tail' catheter was removed the next day.

An office visit on 5/5/2005 revealed a healed wound and drain site. Her C-reactive protein level was now normal. On her office visit of 6/15/2005, she noted slow steady weight gain. At the 1 st annual office visit $\mathrm{s} / \mathrm{p}$ lumbar fusion, she had solid $\mathrm{x}$-ray evidence of healed L5/S1 fusion with intact instrumentation. On her 2nd annual office visit 10/17/2006, she had no recurrence of infection.

\section{DISCUSSION}

This case demonstrates the insidious onset of the infection despite the initial healing post-surgical wound (Pruitt et al., 1993; Hand and Sanford, 1970; Chada et al., 1998; Cobbett, 1918), the lack of response to surgical drainage alone (Widgerow et al., 1995; Smith, 1976; Plaus and Hermann, 1991), the importance of expanding the extent of anatomic imaging studies, the role of interventional CT guided biopsy and drainage (Pruitt et al., 1993; Brown et al., 1999) and the role of antibiotic therapy with multiple antibiotics (Prosser, 1986; Hasegawa et al., 1992). This study suggests that these atypical mycobacterial infections-like their TB counterparts-can be resolved in the face of retained hardware with aggressive medical treatment of these infections (Jain et al., 2007; Chen et al., 2011; Fukuta et al., 2003; Kim et al., 2004; Rappaport et al., 1990; Guven et al., 1994; Swanson et al., 2006)-although other opinions exist (Plaus and Hermann, 1991; Hasegawa et al., 1992).

\section{CONCLUSION}

I would like to thank the numerous collaborators that assisted me with caring for this patient and writing this report: Dr. Joseph Alexander, MD, Dr. Jon 
Thomas, PhD and our WCA Librarians, Ms. Bonnie Engberg and Ms. Mary Franklin.

\section{REFERENCES}

Astageneau, P., N. Desplaces, V. Vincent, V. Chicheportiche and A.H. Botherel et al., 2001. Mycobacterium xenopi spinal infections after discovertebral surgery: investigation and screening of a large outbreak. Lancet, 358: 747-751. PMID: 11551599

Brown, B.A., B. Springer, V.A. Steingrube, R.W. Wilson and G.E. Pfyffer et al., 1999. Mycobacterium wolinskyi sp. Nov. and Mycobacterium goodie sp. Nov., two new rapidly growing species related to Mycobacterium Smegmatis and associated with human wound infections: A cooperative study from the international working group on mycobacterial taxonomy. Int. J. Syst. Bacteriol., 49: 1493-1511. PMID: 10555330

Bullin, C.H., E.I. Tanner and C.H. Collins, 1970. Isolation of Mycobacterium xenopei from water taps. J. Hygiene, 68: 97-100. http://www.ncbi.nlm.nih.gov/pmc/articles/PMC213 0776/

Chada, R., M. Grover, A. Sharma, A. Lakshmy and M. Deb et al., 1998. An outbreak of post-surgical wound infections due to Mycobacterium abscessus. Pediatr. Surg. Int., 13: 406-410. PMID: 9639628

Chen, W.-H., L.-S. Jiang and L.-Y. Dai, 2011. Influence of bacteria on spinal implant-centered infection. Spine, 36: 103-108. DOI: 10.1097/BRS.0b013e3181cb46ba

Cobbett, L., 1918. An acid-fast bacillus obtained from a pustular eruption. Br. Med. J., 2: 158-159. PMID: 20769139

Collins, C.H., J.M. Grange and M.D. Yates, 1984. Mycobacteria in water. J. Applied Bacteriol., 57: 193-211. PMID: 6389461

Corpe, R.F., C.E. Smith and I. Stergus, 1961. Death due to mycobacterium fortuitum. J. Am. Med. Assoc., 177: 262-263. DOI: 10.1001/jama.1961.73040300015012a

Danesh-Clough, T., J.-C. Theis, A.V. der Linden, 2000. Mycobacterium xenopi infection of the Spine. Spine, 25: 626-628. PMID: 10749641

Duttaroy, B., C. Agrawal and A. Pendse, 2004. Spinal Tuberculosis due to dissemination of atypical mycobacteria. Ind. J. Med. Sci., 58: 203-205. PMID: 15166469

Fukuta, S., K. Miyamato, T. Masuda, H. Hosoe and H. Kodama et al., 2003. Two-stage (posterior and anterior) surgical treatment using posterior spinal instrumentation for pyogenic and tuberculotic spondylitis. Spine, 28: E302-306. PMID: 12897509

Guven, O., K. Kumano, S. Yalcin, M. Karahan and S. Tsuji, 1994. A single stage posterior approach and rigid fixation for preventing kyphosis in the treatment of spinal tuberculosis. Spine, 19: 10391043. PMID: 8029738

Han, X.Y., D.E., Indra and K.L. Jacobson, 2007. Rapidly growing mycobacteria: Clinical and microbiologic studies of 115 cases. Am. J. Clin. Pathol., 128: 612-621. PMID: 17875513

Hand, W.L. and J.P. Sanford, 1970. Mycobacterium fortuitum: A human pathogen. Ann. Intern. Med., 73: 971-977. PMID: 5211741

Hasegawa, T., R. Watanabe, K. Hayashi, A. Inufusa and H. Nakagawa, 1992. Postoperative osteomyelitis due to Mycobacterium fortuitum: A case report. Arch. Orthop. Trauma Surg., 111: 178180. PMID: 1586582

Huang, L., Z. Chen and W. Wang, 2000. [Clinical and pathological analysis of 114 patients with postoperative wound infections by M. Abscessus. Zhonghua Jie He He Hu Xi Za Zhi., 23: 281-283. PMID: 11778218

Jain, A.K., I.K. Dhammi and I. Kumar, 2007. Tuberculosis of the Spine: A review. Clin. Orthop. Relat. Res., 460: 39-49. PMID: 17438468

Kalita, J.B., H. Rahman and K.C. Baruah, 2005. Delayed Post-operative wound infections due to non-tuberculous mycobacterium. Ind. J. Med. Res., 122: 535-539. PMID: 16518006

Kim, D.J., Y.H. Yun, S.H. Moon and K.D. Riew, 2004. Posterior instrumentation using compressive laminar hooks and anterior interbody arthrodesis for the treatment of tuberculosis of the lower lumbar Spine. Spine, 29: 275-279. PMID: 15223949

Le Dantec, C., J.-P. Duguet, A. Montiel, N. Dumoutier and S. Dubrou et al., 2002. Occurrence of mycobacteria in water treatment lines and in water distribution systems. Applied Environ. Microbiol., 68: 5318-5325. PMID: 12406720

Marks, J. and H. Schwabacher, 1965. Infection due to mycobacterium xenopei. British Med. J., 1: 32-33. http://www.ncbi.nlm.nih.gov/pmc/articles/PMC216 $7887 /$

Meier, J.L. and S.E. Beekmann, 1995. Mycobacterial and fungal infections of bone and joints. Curr. Opin. $\quad$ Rheumatol., 7: 329-336. http://direct.bl.uk/bld/PlaceOrder.do?UIN=029189 894\&ETOC $=\mathrm{EN} \&$ from $=$ searchengine 
Merani, R., S. Orekondy, T. Gottlieb, P. Janarthanan and S. McCarthy et al., 2008. Postoperative Mycobacterium abscessus nodular conjunctivitis. Clin. Exp. Ophthalmol., 36: 371-373. PMID: 18700926

Nagao, M., M. Sonobe, T. Bando, T. Saito and M. Shirano et al., 2009. Surgical site infection due to Mycobacterium peregrinum: A case report and literature review. Int. J. Infect. Dis., 13: 209-212. DOI: 10.1016/J.IJID.2008.06.018

O'Brien, D.P.K. and D.J. Rawluk, 1999. Iatrogenic mycobacterium infection after an epidural injection. Spine, 24: 1257-1269. PMID: 10382255

Ollagnier, E., A. Fresard, C. Guglielminotti, A. Carricajo and J.F. Mosnier et al., 1998. Osteoarticular Mycobacterium xenopi infection. Presse Med., 27: 800-803. PMID: 9767883

Plaus, W.J. and G. Hermann, 1991. The surgical management of superficial infections caused by atypical mycobacteria. Surgery, 110: 99-103. PMID: 1866699

Prosser, A.J., 1986. Spinal infection with Mycobacterium Xenopi. Tubercle, 67: 229-232. PMID: 3775874

Pruitt, T.C., L.O. Hughes, R.D. Blasier, R.E. McCarthy and C.M. Glasier et al., 1993. Atypical mycobacterial vertebral osteomyelitis in a steroiddependent adolescent: A case report. Spine, 18: 2553-2555. PMID: 8303466

Rahman, M.A., V. Phongsathorn, T. Hughes and C. Bielawska, 1992. Spinal infection by mycobacterium xenopi in a nonimmunosuppressed patient. Tuber. Lung Dis., 73: 392-395. PMID: 1292722

Rappaport, W., G. Dunington, L. Norton, D. Ladin and E. Peterson et al., 1990. The surgical management of atypical mycobacterial soft-tissue infections. Surgery, 108: 36-39. PMID: 2360188

Roche, B., S. Rozenberg, E. Cambau, N. Desplaces and E. Dion et al., 1997. Efficacy of combined clarithromycin and sparfloxacin therapy in a patient with discitis: Due to Mycobacterium xenopi. Rev. Rhum. Engl. Ed., 64: 64-65. PMID: 9051864

Schulze-Robbecke, R., B. Janning and R. Fischeder, 1992. Occurrence of mycobacteria in biofilm samples. Tuber. Lung Dis., 73: 141-44. PMID: 1421346

Slosarek, M., M. Kubin and M. Jaresova, 1993. Waterborne household infections due to Mycobacterium xenopi. Cent. Eur. J. Public Health, 1: 78-80. PMID: 8004044
Smith, E.R., 1976. Mycobacterium fortuitum spinal infection: Case report. Pathology, 8: 289-292. PMID: 1018945

Sumner, C.J., M. Newman and C.A. Jay, 2003. Recurrent myelopathy after HAART in a patient with spinal mycobacterial infection. Neurology, 61: 139-140. PMID: 12847179

Swanson, A.N., I.P. Pappou, F.P. Cammisa and F.P. Girardi, 2006. Chronic infections of the Spine: Surgical indications and treatments. Clin. Orthopaedics Related Res., 444: 100-106. DOI: 10.1097/01.blo.0000203447.44146.55

Thami, G.P., S. Kaur, J. Chander and A.K. Attri, 2002. Post surgical atypical mycobacterial infection due to mycobacterium fortuitum. J. Infect., 45: 210211. PMID: 12387784

Wallace, R.J., 1987. Nontuberculous mycobacteria and water: A love affair with increasing clinical importance. Infect. Dis. Clin. North Am., 1: 677686. PMID: 3332890

Wallace, R.J., B.A. Brown and D.E. Griffith, 1998. Nosocomial outbreaks/pseudo-outbreaks caused by Nontuberculous mycobacteria. Annu. Rev. Microbiol., 52: 453-490. PMID: 9891805

Wallace, R.J., D.R. Nash, M. Tsukamura, Z.M. Blacklock and V.A. Silcox, 1988. Human disease due to mycobacterium smegmatis. J. Infect. Dis., 158: 52-59. PMID: 3392420

Watanakunakorn, C. and A. Trott, 1973. Vertebral osteomyelitis due to Mycobacterium kansasii. Am. Rev. Respir. Dis., 107: 846-850. PMID: 4695636

Weed, L.A., J.R. McDonald and G.M. Needham, 1956. The isolation of "Saphrophytic" acid-fast bacilli from lesions of caseous granulomas. Proc. Staff Meet. Mayo Clin., 18: 246-259. PMID: 13323041

Widgerow, A.D., A.J. Brink and H.J. Koornhof, 1995. Atypical Mycobacterium and breast surgery. Ann. Plast. Surg., 35: 204-207. PMID: 7486746

Wright, E.P., C.H. Collins and M.D. Tates, 1985. Mycobacterium xenopi and Mycobacterium kansasii in a hospital water supply. J. Hosp. Infect., 6: 175-178. PMID: 2862192

Yano, T., S. Okuda, K-I. Kato, K. Kato and T. Kishimoto, 2004. Mycobacterium Kansasii osteomyelitis in a patient with AIDS on highly active antiretroviral therapy. Intern. Med., 43: 1084-1086. PMID: 15609709 